\title{
Lixiviação de nitrato de um substrato minerado tratado com lodo de esgoto doméstico
}

\author{
Rodrigo Ávila de Paula ( $\left.{ }^{1}\right)$; Rodrigo Studart Corrêa $\left(2^{*}\right)$; Taís Pitta Cotta ( $\left.{ }^{3}\right)$ \\ (')Departamento de Engenharia Florestal da Universidade de Brasília. Campus Darcy Ribeiro, FT/EFL, 70910-970 Brasília (DF). \\ E-mail: rods108@yahoo.com.br \\ (2)Departamento de Ecologia da Universidade de Brasília. Caixa Postal 04.401, 70910-900 Brasília (DF). E-mail: rodmanga@yahoo. \\ com.br $\left({ }^{*}\right)$ Autor correspondente. \\ (3)Laboratório de Química Analítica da Universidade de Brasília. Caixa Postal 04.478, 70904-970 Brasília (DF). E-mail: pittagc@unb.br
}

Recebido: 27/jan./2010; Aceito: 27/mai./2010

\section{Resumo}

Lodos de esgoto são fontes significativas de N, P, matéria orgânica e outros elementos necessários à nutrição de plantas. A aplicação desses resíduos em solos e substratos é um das mais eficientes maneiras de recuperação de nutrientes. Todavia, os benefícios obtidos com o uso de lodo de esgoto devem ser confrontados com riscos inerentes à sua utilização, tais como a lixiviação excessiva de nitrato, que pode contaminar aquíferos. Normas sanitárias e ambientais impedem o consumo humano de águas com concentrações de nitrato $\geq 10 \mathrm{mg} \mathrm{L}^{-1}$. Dessa forma, este trabalho objetivou mensurar o risco de contaminação de águas subterrâneas por nitrato produzido em substrato exposto pela mineração, que foi tratado com a dose equivalente a $120 \mathrm{t} \mathrm{ha}^{-1}$ de lodo de esgoto, base úmida. O substrato liberou lixiviados com concentrações de até $78 \mathrm{mg} \mathrm{L}^{-1}$ de nitrato, que representam risco de contaminação de águas subterrâneas. Sob as condições testadas neste trabalho, o aquífero subterrâneo deve situar-se a pelo menos 4,5 m de profundidade, para que o lixiviado liberado da camada tratada com lodo de esgoto seja diluído ao longo do perfil de solo a concentrações $\leq 10 \mathrm{mg} \mathrm{L}^{-1}$, caso a área permaneça sem cobertura vegetal. 0 estabelecimento de uma cobertura herbácea sobre o substrato reduziu em 40\% a quantidade de nitrato liberada no lixiviado, permitindo que o aquífero esteja a 2,7 m de profundidade sem que haja aporte excessivo de nitrato proveniente da camada superficial tratada.

Palavras-chave: biossólido, nitrato, mineralização, nitrificação, aquífero.

\section{Nitrate leaching from a mined spoil treated with domestic sewage sludge}

\begin{abstract}
Sewage sludges are significant sources of N, P, organic matter, and other elements for plant nutrition. Soil and spoil application of such residues is one of the most efficient ways of nutrient recovery. However, the benefits from sewage sludge soil application have to be weighed against sanitary and environmental risks such as excessive nitrate leaching, which may contaminate water. Sanitary and environmental regulations have banned human consumption of waters with nitrate concentrations $\geq 10 \mathrm{mg} \mathrm{L}^{-1}$. Therefore, this work aimed to measure the risk of groundwater contamination by nitrate produced in a mined spoil treated with $120 \mathrm{t} \mathrm{ha}^{-1}$ of domestic sewage sludge on wet basis. The amended spoil leached solutions with concentrations up to $78 \mathrm{mg} \mathrm{L}^{-1}$ of nitrate, which poses risks to underground water. Under the experimental conditions set in this work, the groundwater table has to rest at $4.5 \mathrm{~m}$ depth or deeper to allow the leachate diluting through the soil profile to concentrations $\leq 10 \mathrm{mg} \mathrm{L}^{-1}$, if the soil remains bare. A grass cover on the amended spoil decreased by $40 \%$ the amount of nitrate in the leachate and it would allow a groundwater table at $2.5 \mathrm{~m}$ depth without an excessive nitrate input from the top sewage sludge amended layer.
\end{abstract}

Key words: biosolids, nitrate, mineralization, nitritication, underground water. 


\section{INTRODUÇÃO}

Esgotos domésticos e subprodutos de seu tratamento, tais como lodo de esgoto, são fontes significativas de N, P, matéria orgânica e outros elementos necessários à nutrição de plantas (Plachá et al., 2008). Retornar matéria orgânica e nutrientes aos seus ciclos naturais representa a base ideológica para se aplicar lodo de esgoto e seus derivados em solos. Essa solução tem sido considerada aceitável, desde que atenda a normas sanitárias e ambientais (RATHOD et al., 2009).

A aplicação em solos é uma das mais eficientes práticas de disposição de lodo de esgoto e de recuperação de nutrientes que, geralmente, tornam-se disponíveis para as plantas por meio da mineralização da fração orgânica (ANDrade et al., 2006; NóvoA-MuŃoz et al., 2008). Entretanto, as características físicas, químicas e biológicas desse material representam preocupaçôes para seu manejo adequado (O'Kelly, 2008). Os benefícios obtidos com o uso do lodo devem ser confrontados com os perigos e os possíveis riscos inerentes à sua utilizaçáo (Pengcheng et al., 2008), tais como lixiviação excessiva de nitrato, contaminação de solos, culturas e animais por patógenos e metais, entre outros (Oliveira et al., 2001; Piovesan et al., 2009).

Água com concentraçôes a partir de $10 \mathrm{mg} \mathrm{L}^{-1} \mathrm{de}$ nitrato $\left(\mathrm{NO}_{3}^{-}\right)$são consideradas tóxicas, pois o $\mathrm{NO}_{3}$ pode ser reduzido a nitrito $\left(\mathrm{NO}_{2}^{-}\right)$no intestino humano e causar metamoglobinemia em crianças pequenas (Haering et al., 2000). Por esse motivo, a lixiviação de $\mathrm{NO}_{3}^{-}$e a consequente contaminação de aquíferos são os fatores que mais limitam aplicações periódicas de lodo de esgoto em uma mesma área (Polgase e Robison, 1996; Oliveira et al., 2001).

Para se evitar a contaminação de águas subterrâneas por nitrato, a dose de aplicação de lodo de esgoto deve considerar, pelo menos, duas variáveis: a taxa de mineralização do $\mathrm{N}$ orgânico no solo em que o resíduo foi incorporado e a necessidade de $\mathrm{N}$ pela cultura a ser cultivada com esse resíduo (Haynes et al., 2009). A mineralização de materiais orgânicos em solos é o principal processo que influencia o suprimento de $\mathrm{N}$ para as plantas e também para a lixiviação (O'Dowd et al., 1999; PiOvesan et al., 2009).

Nesse contexto, a coleta e o tratamento de esgotos no Distrito Federal (DF) superam 90\% da quantidade gerada por uma população de aproximadamente 2,2 milhões de habitantes. Essa população resulta na produção de quase $400 \mathrm{t}$ por dia de lodo de esgoto, que devem ser adequadamente gerenciadas e depositadas no ambiente. Até 2003, 95\% do lodo de esgoto gerado no Distrito Federal eram destinados a solos sob produção agrícola (CAEsB, 2005). Entretanto, a falta de regulamentaçáo para o uso desse resíduo na agricultura e a contaminação química e biológica de uma captação de água para abastecimento público provocaram a suspensão do uso agrícola desse material no DF até que sua utilização fosse regulamentada.

Como alternativa de disposição, os lodos de esgotos produzidos no DF têm sido incorporados às camadas superficiais de jazidas mineradas, mesmo após a edição de normas federal e distrital que regulamentam seu uso agrícola (ConAm/DF, 2006; ConAma, 2006), florestal, em pesquisas e em áreas mineradas (CoNAM/DF, 2006). Atividades minerárias expóem à superfície substratos que demandam grande quantidade de matéria orgânica para serem revegetados (CorrêA et al., 2008) e as jazidas explotadas apresentam menos restriçôes legais, sanitárias e ambientais que solos agrícolas em relação à aplicação de lodo de esgoto (Conan/DF, 2006; Conama, 2006).

Dessa forma, com base em autorizações expedidas pelo órgão ambiental, os lodos produzidos no DF têm sido incorporados a substratos de jazidas explotadas em doses superiores a $100 \mathrm{t} \mathrm{ha}^{-1}$ de matéria úmida ou $12 \mathrm{t} \mathrm{ha}^{-1} \mathrm{de}$ matéria seca. Esse manejo estimula o surgimento quase imediato de um estrato herbáceo nas jazidas, composto principalmente por Brachiaria spp. (Bento, 2009). Apesar das menores restrições sanitárias que a deposição de lodo de esgoto em jazidas mineradas demanda, o risco de contaminação de águas subterrâneas por nitrato deve ser avaliado.

Em face do exposto e com o objetivo de se avaliar o risco de contaminação de águas subterrâneas, as concentraçóes e quantidades de nitrato lixiviado de um substrato tratado com lodo de esgoto foram mensuradas, na presença e na ausência de uma cobertura herbácea. De posse desses dados, modelou-se a profundidade mínima que aquíferos devem resguardar da camada superficial tratada com lodo de esgoto para que a solução lixiviada chegue às águas subterrâneas com concentrações de nitrato $\leq 10 \mathrm{mg} \mathrm{L}^{-1}$.

\section{MATERIAL E MÉTODOS}

\section{Lodo de esgoto}

Uma amostra de $20 \mathrm{~kg}$ de lodo de esgoto foi obtida na Estação de Tratamento de Esgoto Brasília Norte, operada pela Companhia de Saneamento Ambiental do Distrito Federal - Caesb. Tratava-se de uma mistura de lodo originado pelos tratamentos primário, secundário (lodo biologicamente ativado) e terciário [polido com $\left.\mathrm{Al}_{2}\left(\mathrm{SO}_{4}\right)_{3}\right]$. A mistura composta pelos três tipos de lodo foi desaguada em prensa mecânica e o resíduo foi liberado para o pátio de estocagem contendo $88 \mathrm{dag} \mathrm{kg}^{-1} \mathrm{de}$ teor de água (Tabela 1).

\section{Substrato}

Cerca de $200 \mathrm{~kg}$ do horizonte C de um Cambissolo (EMBrapa, 1999) foi coletado da superfície de uma jazida 
explotada de cascalho na área do Campus Darcy Ribeiro da Universidade de Brasília (Tabela 1). A amostra de substrato foi deixada para secar à sombra por duas semanas e em seguida passada em peneira de $2 \mathrm{~mm}$ de abertura. A densidade de solo (Ds) e a capacidade de campo (CC) do substrato foram mensuradas conforme descrito em Cassel e Nielsen (1986).

\section{Experimento}

O substrato foi tratado com uma dose equivalente a 120 t ha ${ }^{-1}$ de lodo de esgoto, contendo $88 \mathrm{dag} \mathrm{kg}^{-1}$ de teor de água, para um experimento de lixiviação em potes, em casa de vegetação. A dose aplicada equivale a 14,4 t $\mathrm{ha}^{-1}$ de massa seca ou a $0,79 \mathrm{t} \mathrm{ha}^{-1}$ de $\mathrm{N}$ total (Tabela 1 ). Métodos que envolvem a mineralização de materiais orgânicos incubados em solos são considerados apropriados para se estimar taxas de mineralizaçáo e lixiviação de $\mathrm{N}$ (Van Kessel et al., 2000; Andrade et al., 2006; Boeira e Maximiliano, 2009).

Amostras de 1,4 kg do substrato tratado com lodo de esgoto foram usadas para preencher os vintes primeiros centímetros de vinte potes cilíndricos de $10 \mathrm{~cm}$ de diâmetro e $2 \mathrm{~L}$ de capacidade, confeccionados em politereftalato de etileno e com base afunilada. A base afunilada de cada pote foi envolvida com lá de vidro e papel Whatman 42 para filtragem do lixiviado drenado dos substratos. Dez potes contendo substrato não tratado foram inseridos no experimento para efeito de controle. Todos os potes foram mantidos sob condiçáo de umidade equivalente a da capacidade de campo, com a utilizaçáo de água destilada, durante todo o experimento, que foi instalado em casa de vegetação.

Para se averiguar a influência da vegetação sobre a lixiviação de nitrato, dez potes receberam cada um seis sementes da espécie herbácea Brachiaria brizantha cv. Marandu (capim marandu). Duas semanas após a germinação das sementes, três indivíduos foram desbastados em cada pote, deixando-se os três indivíduos em melhores condiçóes visuais de desenvolvimento e fitossanidade.

Uma solução de $\mathrm{CaCO}_{3}$ 0,01 mol L-1 (chuva sintética) foi utilizada para simular as quantidades mensais de água drenada nos meses em que a precipitação pluvial supera a evapotranspiração no Distrito Federal (Tabela 2) e, consequentemente, a drenagem é positiva (SHAFFER et al., 1991). A quantidade de chuva sintética aplicada mensalmente aos substratos considerou, dessa forma, a diferença entre a precipitação e a evapotranspiração real

Tabela 1. Característica do lodo de esgoto e do substrato minerado utilizados (Resultados em base seca, salvo quando indicado *base úmida)

\begin{tabular}{|c|c|c|}
\hline Parâmetro & $\begin{array}{l}\text { Lodo de } \\
\text { esgoto }\end{array}$ & $\begin{array}{l}\text { Substrato } \\
\text { minerado }\end{array}$ \\
\hline Densidade $\left(\mathrm{t} \mathrm{m}^{-3}\right)$ & $1,1-1,2$ & $1,3-1,4$ \\
\hline Capacidade de campo $\left(\mathrm{m}^{3} \mathrm{~m}^{-3}\right)$ & & $0,35-0,40$ \\
\hline $\mathrm{pH}_{\text {água }}$ & 6,3 & $5,0-5,3$ \\
\hline $\mathrm{pH}_{\mathrm{KCl}}$ & $5,9-6,0$ & $4,9-5,2$ \\
\hline Umidade (dag $\left.\mathrm{kg}^{-1}\right)$ & $86-88$ & - \\
\hline Carbono orgânico $\left(\mathrm{g} \mathrm{kg}^{-1}\right)$ & $310-330$ & $0,4-0,6$ \\
\hline Nitrogênio total $\left(\mathrm{g} \mathrm{kg}^{-1}\right)$ & $51-59$ & $<0,01$ \\
\hline Fósforo total $\left(\mathrm{g} \mathrm{kg}^{-1}\right)$ & $31-60$ & $<0,01$ \\
\hline Potássio $\left(\mathrm{g} \mathrm{kg}^{-1}\right)$ & $2-6$ & $0,01-0,03$ \\
\hline Cálcio (g kg-1) & $5-20$ & $0,01-0,04$ \\
\hline Magnésio $\left(\mathrm{g} \mathrm{kg}^{-1}\right)$ & $2-6$ & $<0,01$ \\
\hline Alumínio $\left(\mathrm{g} \mathrm{kg}^{-1}\right)$ & $2-4$ & $<0,01$ \\
\hline Ferro $\left(\mathrm{g} \mathrm{kg}^{-1}\right)$ & $1-2$ & $0,01-0,02$ \\
\hline Arsênio (mg kg-1) & $0,1-0,6$ & - \\
\hline Cádmio (mg kg-1) & $4-6$ & - \\
\hline Chumbo (mg kg-1) & $10-11$ & - \\
\hline Cobre $\left(\mathrm{mg} \mathrm{kg}^{-1}\right)$ & 87 a 104 & $<0,01$ \\
\hline Cromo $\left(\mathrm{mg} \mathrm{kg}^{-1}\right)$ & $18-21$ & - \\
\hline Manganês (mg kg-1) & $75-83$ & $<0,01$ \\
\hline Mercúrio (mg kg-1) & $1-4$ & - \\
\hline Molibdênio (mg kg-1) & $3-7$ & $<0,01$ \\
\hline Níquel (mg kg-1) & $5-6$ & - \\
\hline Zinco (mg kg-1) & $159-169$ & - \\
\hline
\end{tabular}

Tabela 2. Dados climáticos do Distrito Federal (Série histórica de trinta anos)

\begin{tabular}{|c|c|c|c|c|}
\hline \multirow{2}{*}{ Mês } & Precipitação pluvial & Evapotranspiração Real & Drenagem & Temperatura média do ar \\
\hline & \multicolumn{3}{|c|}{ mm } & ${ }^{\circ} \mathrm{C}$ \\
\hline Janeiro & 241,6 & 36,5 & 212,4 & 22,2 \\
\hline Fevereiro & 213,5 & 32,9 & 187,18 & 22,1 \\
\hline Março & 188,2 & 43,8 & 153,16 & 22,0 \\
\hline Abril & 123,6 & 36,5 & 94,4 & 22,2 \\
\hline Maio & 36,5 & 69,4 & $-19,02$ & 21,0 \\
\hline Junho & 5,6 & 98,6 & $-73,28$ & 20,3 \\
\hline Julho & 8,4 & 138,8 & $-102,64$ & 20,1 \\
\hline Agosto & 11,2 & 208,1 & $-155,28$ & 22,0 \\
\hline Setembro & 39,3 & 197,2 & $-118,46$ & 23,2 \\
\hline Outubro & 171,3 & 102,2 & 89,54 & 24,0 \\
\hline Novembro & 238,8 & 36,5 & 209,6 & 22,3 \\
\hline Dezembro & 250,0 & 21,9 & 232,48 & 22,3 \\
\hline Total & $1.528,0$ & $1.022,4$ & 710,1 & \\
\hline
\end{tabular}

Fonte: Inmet (2007). 
no Distrito Federal, que representa $80 \%$ de sua evapotranspiração potencial (White, 1997). A solução drenada dos substratos em cada mês foi coletada e medida em proveta com $1 \mathrm{~mL}$ de precisão.

\section{Análises laboratoriais}

Os lixiviados coletados foram armazenados em frascos de $50 \mathrm{~mL}$, dotados de tampas com rosca, e congelados no mesmo dia da coleta. As concentraçôes de nitrato foram determinadas em espectrofotômetro B382 Micronal, por meio de espectroscopia de absorção na regiáo do ultravioleta (SKOog et al., 2002). Os resultados das concentraçóes de $\mathrm{N}_{-} \mathrm{NO}_{3}{ }^{-}$nos lixiviados foram analisados pelo teste nãoparamétrico de Miller, a $\mathrm{p} \leq 0,05$ de significância, pois concentraçóes de nitrato $\left(\mathrm{NO}_{3}^{-}\right)$não têm distribuição normal na natureza (EDIs, 1998). Conjuntos de dados com distribuição normal foram analisados por meio de ANOVA e teste de Tukey a $\mathrm{p} \leq 0,05$ de significância.

\section{Modelagem}

A modelagem de lixiviação de $\mathrm{N}^{-\mathrm{NO}_{3}}{ }^{-}$considerou dois fatores: a produção de $\mathrm{N}_{-} \mathrm{NO}_{3}{ }^{-}$nos substratos e seu transporte pela drenagem ao longo de um perfil homogêneo (White et al., 1998). A lixiviaçáo de $\mathrm{NO}_{3}^{-}$pode ser simulada por meio de vários modelos em diferentes níveis de complexidade. $\mathrm{O}$ modelo utilizado neste trabalho considerou o balanço hídrico simplificado e a quantidade de $\mathrm{N}-\mathrm{NO}_{3}$ - disponível para ser lixiviado da camada tratada. Shaffer et al. (1991) estimulam o uso desse método como primeira aproximação para a avaliação do risco de lixiviação de $\mathrm{NO}_{3}^{-}$de solos e o uso de métodos mais sofisticados caso o risco se mostre significativo.

A profundidade alcançada pelo solo lixiviado que deixou a camada superficial $(0-20 \mathrm{~cm})$ de substrato tratado foi calculada de acordo com White (1997):

$z(t)=\frac{D}{C C}$ (Equação 1)

em que:

Z é a distância $(\mathrm{mm})$ percorrida pela soluçâo drenada ao longo do perfil de solo;

t é o período de tempo modelado (mês, ano, outros);

$\mathrm{D}$ é a água/solução disponível para drenagem $(\mathrm{mm})$;

CC é a capacidade de campo do solo/substrato $\left(\mathrm{m}^{3} \mathrm{~m}^{-3}\right)$.

\section{RESULTADOS E DISCUSSÃO}

A acumulaçấo de nitrato $\left(\mathrm{NO}_{3}^{-}\right)$em solos deve ser evitada por razôes sanitárias e ambientais (CORRÊA et al., 2005;
Piovesan et al., 2009). Contudo, solos e substratos tratados com lodo de esgoto possuem intensa nitrificação (Vieira e Cardoso, 2003; CorrêA et al., 2005) e a incorporaçáa de lodo de esgoto ao substrato minerado (120 t $\mathrm{ha}^{-1}, 88 \mathrm{dag} \mathrm{kg}^{-1}$ de teor de água) resultou no aumento significativo $(\mathrm{p}<0,05)$ das concentraçóes de $\mathrm{N}_{-} \mathrm{NO}_{3}{ }^{-}$nos lixiviados recolhidos (Figura 1).

Os substratos tratados com lodo de esgoto liberaram, no primeiro mês de incubaçáo, lixiviados com concentraçáo média de 12,2 $\pm 0,11 \mathrm{mg} \mathrm{L}^{-1}$ de $\mathrm{N}-\mathrm{NO}_{3}^{-}$. Nos dois meses

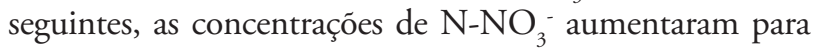
valores entre 58 e $78 \mathrm{mg} \mathrm{L}^{-1}$ e mantiveram-se nesse nível até o fim do experimento no substrato tratado com lodo que não foi cultivado com Brachiaria brizantha cv. Marandu capim marandu (Figura 1). Outros trabalhos concluíram que a incorporaçáo de doses entre 33 e $78 \mathrm{t} \mathrm{ha}^{-1}$ de lodo de esgoto a Latossolos gera riscos de contaminação de águas subterrâneas por $\mathrm{NO}_{3}^{-}$(Anjos e Mattiazzo, 2000; OliveIRA et al., 2001). Concentraçóes $\mathrm{NO}_{3}^{-}$aumentam significativamente a partir do segundo mês após a incorporação de lodo de esgoto em solos, quando a mineralização já liberou $\mathrm{NH}_{4}{ }_{4}^{+}$suficiente e a nitrificação pode ocorrer (Oliveira et al., 2001; Vieira e Cardoso, 2003).

As sementes de capim marandu germinaram após três semanas do início do experimento e as plântulas que foram mantidas se desenvolveram em todos os potes semeados. O efeito do capim sobre as concentraçôes de nitrato nos lixiviados foi percebido a partir do fim do terceiro mês de incubação (março), quando a drenagem coletada nesse tratamento começou a ter concentraçóes reduzidas de $\mathrm{N}_{-} \mathrm{NO}_{3}^{-}$em relação ao mês anterior (fevereiro) e ao substrato tratado com lodo que se manteve desprovido de vegetação. As diferenças entre as concentraçôes de $\mathrm{N}^{-\mathrm{NO}_{3}}$ no lixiviado dos dois tratamentos se acentuaram nos meses seguintes, tornando-se significativas $(\mathrm{p}<0,05)$ a partir do quarto mês após o início do experimento (Figura 1).

Em outubro, quando se reinicia o período chuvoso no Distrito Federal, não havia diferença significativa entre as concentraçóes de $\mathrm{N}^{-\mathrm{NO}_{3}}{ }^{-}$nos lixiviados do substrato controle e do substrato tratado com lodo de esgoto que recebeu cobertura vegetal (Teste de Miller, $p<0,05$ ). As

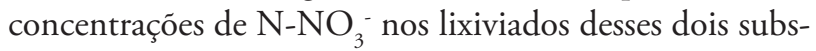
tratos mantinham-se entre 9,8 e $11,1 \mathrm{mg} \mathrm{L}^{-1}$, enquanto no substrato tratado com lodo de esgoto e sem cobertura vegetal o valor atingia $71,7 \pm 0,5 \mathrm{mg} \mathrm{L}^{-1}$. Nos dois meses seguintes (novembro e dezembro), houve redução nas concentraçôes médias dos lixiviados colhidos, sobretudo naqueles tratados com lodo de esgoto e que permanecerem sem cobertura vegetal. A concentração de $\mathrm{N}^{-\mathrm{NO}_{3}^{-}}$ decresceu para $36,5 \pm 0,4 \mathrm{mg} \mathrm{L}^{-1} \mathrm{em}$ novembro e mantevese nesse patamar no mês seguinte. Nos demais substratos (controle e substrato + lodo + gramínea), as concentraçôes de $\mathrm{N}^{-} \mathrm{NO}_{3}^{-}$nos lixiviados mantiveram-se abaixo de 10 $\mathrm{mg} \mathrm{L}^{-1}$ até o fim do experimento (Figura 1). Exaustão da fração mineralizável do $\mathrm{N}$ orgânico e absorção de $\mathrm{N}$ por 
culturas são relatados como os fatores mais importantes pelas reduçóes de nitrato em solos tratados com lodo de esgoto (Laverman, 2000; Oliveira et al., 2001).

A maior quantidade de $\mathrm{N}_{-} \mathrm{NO}_{3}^{-}$liberado pelos subs-

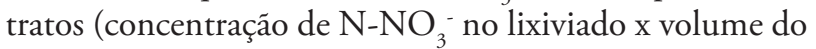
lixiviado) ocorreu no fim de fevereiro (Tabela 3), cerca de dois meses após a incorporaçáo do lodo de esgoto aos

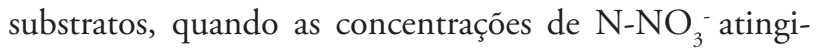
ram valores máximos (Figura 1). No fim do quarto mês de incubação, as diferenças entre as quantidades de $\mathrm{N}_{-} \mathrm{NO}_{3}^{-}$ recuperadas nos lixiviados dos substratos com cobertura vegetal e sem ela tornaram-se significativas (Tabela 3). As plântulas estavam-se enraizadas e em pleno desenvolvimento no fim do segundo mês de incubação, quando a demanda por nutrientes, principalmente $\mathrm{N}\left(\mathrm{NH}_{4}^{+} \mathrm{e}\right.$ $\mathrm{NO}_{3}{ }^{-}$), é elevada (CORRÊA et al., 2008).

A absorção de $\mathrm{N}$ pelas plantas ocorre nas camadas superficiais do solo, onde se distribui a maior parte do sistema radicular e há movimentaçáo de nitrato para zonas mais profundas quando a necessidade da planta por $\mathrm{N}$ é excedida (Dynia, 2000; LaVerman, 2000). Nesse contexto, o substrato tratado com lodo de esgoto que permaneceu sem cobertura vegetal produziu 1,7 vez mais $\mathrm{N}^{-\mathrm{NO}_{3}}{ }_{3}^{-}$no lixiviado que o tratamento que continha o capim B. brizantha e quase cinco vezes mais do que o substrato controle, ao se considerar os sete meses avaliados (Tabela 3). A modelagem de lixiviação de nitrato em solos incubados e sem cobertura vegetal representa o pior cenário ambiental (Laverman, 2000). A diferença de $183,4 \mathrm{mg}$ de $\mathrm{N}_{-} \mathrm{NO}_{3}$ por pote entre o tratamento que recebeu cobertura vegetal $\mathrm{e}$ o que permaneceu sem ela pode ser atribuída à absorção de $\mathrm{N}$ pelas plantas nos sete meses de experimento (Tabela 3).

Em solos tratados com lodo de esgoto existe grande potencial para a lixiviação de nitrato (VIEIRA e Cardoso, 2003) e, de acordo com EdIs (1998), a drenagem é o fator mais importante para a percolação de nitrato em solos. Porém, as concentraçóes (Figura 1) e as quan-

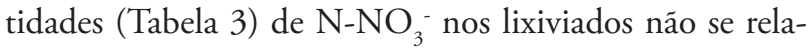
cionaram de maneira significativa à precipitaçáo pluvial média mensal (Tabela $2 ; R^{2}=0,08$ ), ao volume de solução

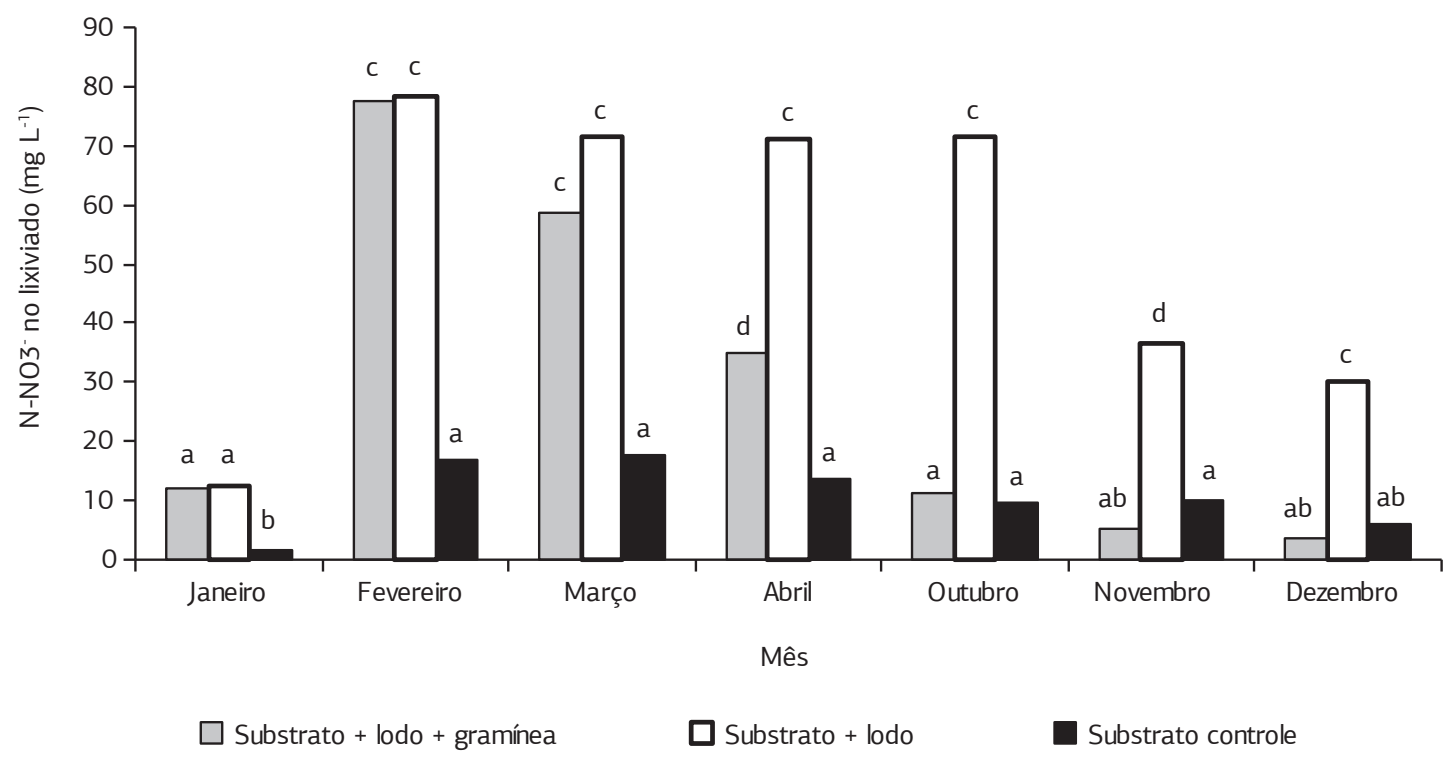

Figura 1. Concentraçôes de $\mathrm{N}_{-} \mathrm{NO}_{3}^{-}$nos lixiviados dos substratos tratados e do controle. Em cada mês, médias com letras iguais não diferem pelo teste de Miller $(\mathrm{p}<0,05)$.

Tabela 3. Quantidades de $\mathrm{NO}_{3}{ }^{-}$recolhidos nos lixiviados dos substratos tratados e do controle

\begin{tabular}{lccc} 
Mês & Substrato + lodo + gramínea & Substrato + lodo & Substrato controle \\
\cline { 2 - 4 } & & $\mathbf{m g}$ & $2,9 \mathrm{~b}$ \\
\hline Janeiro & $20,7 \mathrm{a}$ & $20,9 \mathrm{a}$ & $25,0 \mathrm{~b}$ \\
\hline Fevereiro & $116,0 \mathrm{a}$ & $117,7 \mathrm{a}$ & $21,0 \mathrm{~b}$ \\
\hline Março & $70,3 \mathrm{a}$ & $85,8 \mathrm{a}$ & $9,6 \mathrm{c}$ \\
\hline Abril & $24,4 \mathrm{a}$ & $49,8 \mathrm{~b}$ & $6,9 \mathrm{a}$ \\
Outubro & $7,8 \mathrm{a}$ & $50,2 \mathrm{~b}$ & $16,0 \mathrm{c}$ \\
Novembro & $8,2 \mathrm{a}$ & $58,4 \mathrm{~b}$ & $11,2 \mathrm{c}$
\end{tabular}

Médias de mesma letra em cada linha não diferem pelo Teste de Miller $(\mathrm{p}<0,05)$. 
drenada $\left(\mathrm{R}^{2}=0,05\right)$, à capacidade de campo dos substratos $\left(\mathrm{R}^{2}<0,01\right)$ ou à temperatura média mensal do Distrito Federal $\left(\mathrm{R}^{2}=0,08\right)$. As quantidades de $\mathrm{N}^{-\mathrm{NO}_{3}}{ }^{-}$recolhidas abaixo da camada superficial de $0-20 \mathrm{~cm}$ dependeram das concentraçóes de $\mathrm{N}^{-\mathrm{NO}_{3}}$ - formado nos substratos ( $\square$ $\left.=1,3+1,1^{* *} \mathrm{X} ; \mathrm{R}^{2}=0,82^{*}\right)$. Vários fatores influenciam a formação e a lixiviação de nitrato em solos (Oliveira et al., 2001; Vieira e Cardoso, 2003; Andrade et al., 2006; Piovesan et al., 2009). Todavia, CorrêA et al. (2005) concluíram que a quantidade de nitrato disponível para lixiviar de solos incubados com lodo de esgoto dependiam, sobretudo, da concentração de $\mathrm{NH}_{4}^{+}$nesses solos. Relatam, ainda, que a nitrificação em solos e substratos tratados com lodo de esgoto é uma característica mais relacionada às condições edáficas do que ao tipo do resíduo.
A incorporação de $120 \mathrm{t} \mathrm{ha}^{-1}$ de lodo de esgoto $(14,4$ t matéria seca ha $\left.{ }^{-1}\right)$ não afetou significativamente a capacidade de campo $\left(0,38 \mathrm{~m}^{3} \mathrm{~m}^{-3}\right)$ do substrato minerado (horizonte $\mathrm{C}$ de um Cambissolo). Mudanças nas propriedades físicas de solos e substratos tratados com lodos de esgoto requerem doses mais elevadas, aplicaçôes múltiplas (CorrêA et al., 2005; De MARIA et al., 2007) ou maior tempo de incubação para que haja estruturação do ambiente edáfico. Todavia, ainda que não significante pelo teste de Tukey ( $p>0,10)$, os substratos que foram cultivados com capim marandu tiveram aumento na quantidade de água retida à tensão de $10 \mathrm{kPa}$ de $0,40 \mathrm{~m}^{3} \mathrm{~m}^{-3}$ para $0,46 \mathrm{~m}^{3} \mathrm{~m}^{-3}$ (Figura 2). Como resultado, a profundidade atingida pelos lixiviados em cada mês seguiu a ordem crescente - substrato + lodo + capim < substrato + lodo < substrato controle (Figura 3), ainda que a profundidade

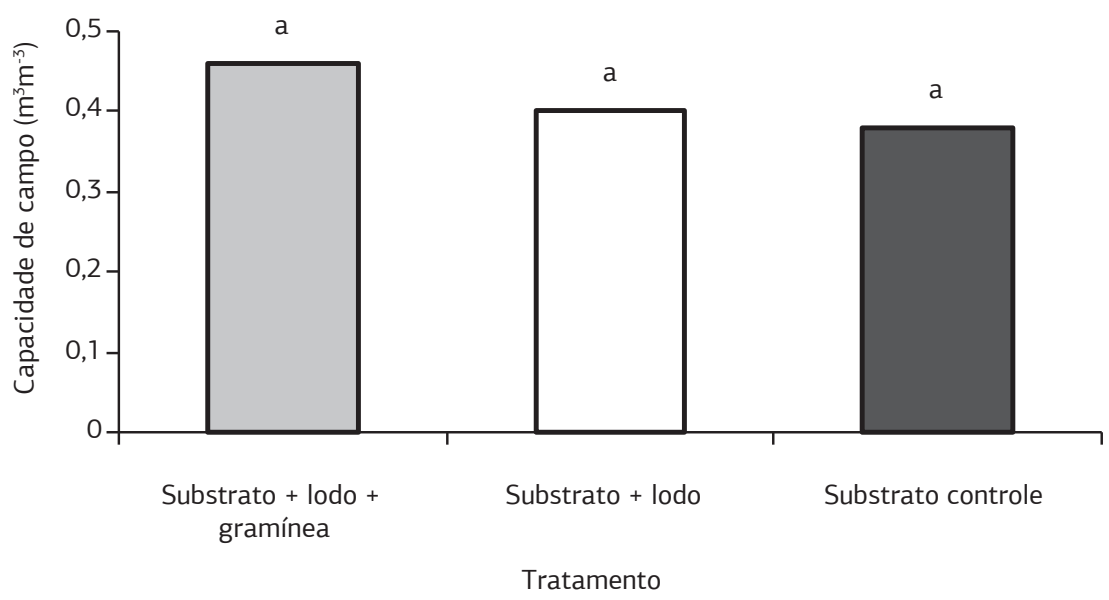

Figura 2. Capacidade de campo $\left(\mathrm{m}^{3} \mathrm{~m}^{-3}\right)$ dos substratos tratados e do controle. Médias com letras iguais nâo diferem pelo teste de Tukey $(\mathrm{p}<0,05)$.

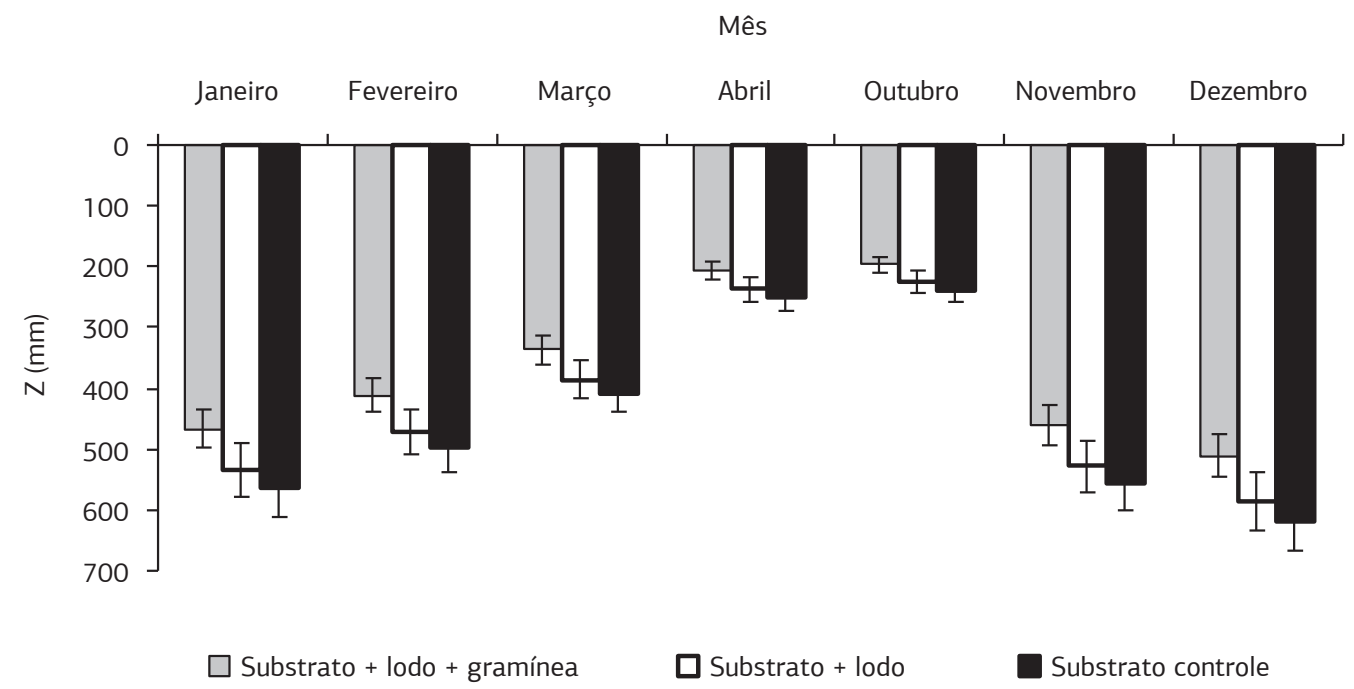

Figura 3. Profundidade mensal de infiltraçáo $(Z)$ dos lixiviados dos substratos tratados e do controle (média de dez repetiçôes \pm desviopadrão). 
atingida pela drenagem a cada mês tenha dependido da precipitaçáo pluvial (Tabela $2 ; \mathrm{Q}=-181,3+2,9^{* *} \mathrm{X} ; \mathrm{R}^{2}=$ $\left.0,83^{*}\right)$ e náo da capacidade de campo dos substratos $\left(\mathrm{R}^{2}\right.$ $=0,03$ ).

As maiores perdas de nitrato de solos tratados com lodo de esgoto ocorrem no início do ciclo de culturas, quando as plantas ainda não estão enraizadas e a exigência por $\mathrm{N}$ é pequena (Lavernan, 2000; Vieira e Cardoso, 2003). O maior risco mensal de contaminação de águas subterrâneas avaliado neste trabalho ocorreu no fim do segundo mês (fevereiro) de incubaçáo do lodo de esgoto nos substratos. O lixiviado recolhido apresentou $78 \mathrm{mg}$ $\mathrm{L}^{-1}$ de $\mathrm{N}^{-N_{3}}{ }_{3}^{-}$(Figura 1) e o modelo (Equação 1) indicou que ele atingiria $47 \mathrm{~cm}$ de profundidade (Figura 3). De acordo com a Equação 1 e considerando o volume e a

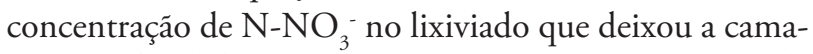
da superficial de $0-20 \mathrm{~cm}$, seriam necessários $3,8 \mathrm{~m}$ de camada de substrato abaixo da camada superficial tratada com lodo de esgoto para que a concentraçáo medida se diluísse até o limite sanitariamente seguro de $10 \mathrm{mg}$ $\mathrm{NO}_{3}^{-} \mathrm{L}^{-1}$.

Em uma escala anual, as $437,1 \mathrm{mg} /$ pote de $\mathrm{N}_{-\mathrm{NO}_{3}}$ recolhidos do substrato que foi tratado com a dose equivalente a $120 \mathrm{t} \mathrm{ha}^{-1}$ de lodo de esgoto e permaneceu sem cobertura vegetal (Tabela 3) seriam diluídos em 710,1 mm de drenagem (Tabela 2) a 76,7 $\mathrm{mg} \mathrm{L}^{-1}$ de $\mathrm{N}_{-\mathrm{NO}_{3}}^{-} \mathrm{e}$ o lixiviado atingiria $1,8 \mathrm{~m}$ de profundidade (Figura 4). Seriam necessários mais dois anos de chuvas para que o lixiviado se diluísse até a concentraçáo de $10 \mathrm{mg} \mathrm{L}^{-1}$ de $\mathrm{N}^{-} \mathrm{NO}_{3}^{-}$, ao atingir a profundidade de $4,5 \mathrm{~m}$. Caso os substratos tratados com lodo de esgoto recebam coberturas compostas por gramíneas, o lixiviado contendo $44,5 \mathrm{~m}$ $\mathrm{L}^{-1}$ de $\mathrm{N}-\mathrm{NO}_{3}$ - percolaria a $1,5 \mathrm{~m}$ de profundidade (Figura 4) e uma camada não tratada de $2,7 \mathrm{~m}$ de profundidade seria suficiente para proteger recursos hídricos subterrâneos. A modelagem de transporte de solutos ao longo de um perfil de solo é especifica. Sob regimes climáticos e condiçôes edáficas diferentes, a contribuição de cada fator que influencia a formação e lixiviação de nitrato muda (White, 1997; Edis, 1988; White et al., 1998; CorrêA et al., 2005).

\section{CONCLUSÕES}

1. A incorporação de $120 \mathrm{t} \mathrm{ha}^{-1}$ de lodo de esgoto $(88$ dag $\mathrm{kg}^{-1}$ de teor de água) na camada superficial (0-20 $\mathrm{cm})$ do substrato minerado libera lixiviados com concentraçóes de ${\mathrm{N}-\mathrm{NO}_{3}}_{3}^{-}$que representam risco de contaminação de águas subterrâneas.

2. O maior risco de contaminação de águas subterrâneas ocorre cerca de dois meses após a incorporação do lodo de esgoto ao substrato, quando a concentração de $\mathrm{N}_{-} \mathrm{NO}_{3}$ - é máxima e as plantas semeadas não utilizam ainda significativas quantidades de $\mathrm{N}$ mineral.

3. O estabelecimento de uma cobertura composta por Brachiaria brizantha cv. Marandu reduz a quase metade a quantidade de $\mathrm{N}-\mathrm{NO}_{3}{ }^{-}$disponível para lixiviar.

4. A incorporação da dose única de $120 \mathrm{t} \mathrm{ha}^{-1}$ de lodo de esgoto (88 dag kg-1 de teor de água) na camada superficial do substrato minerado no Distrito Federal

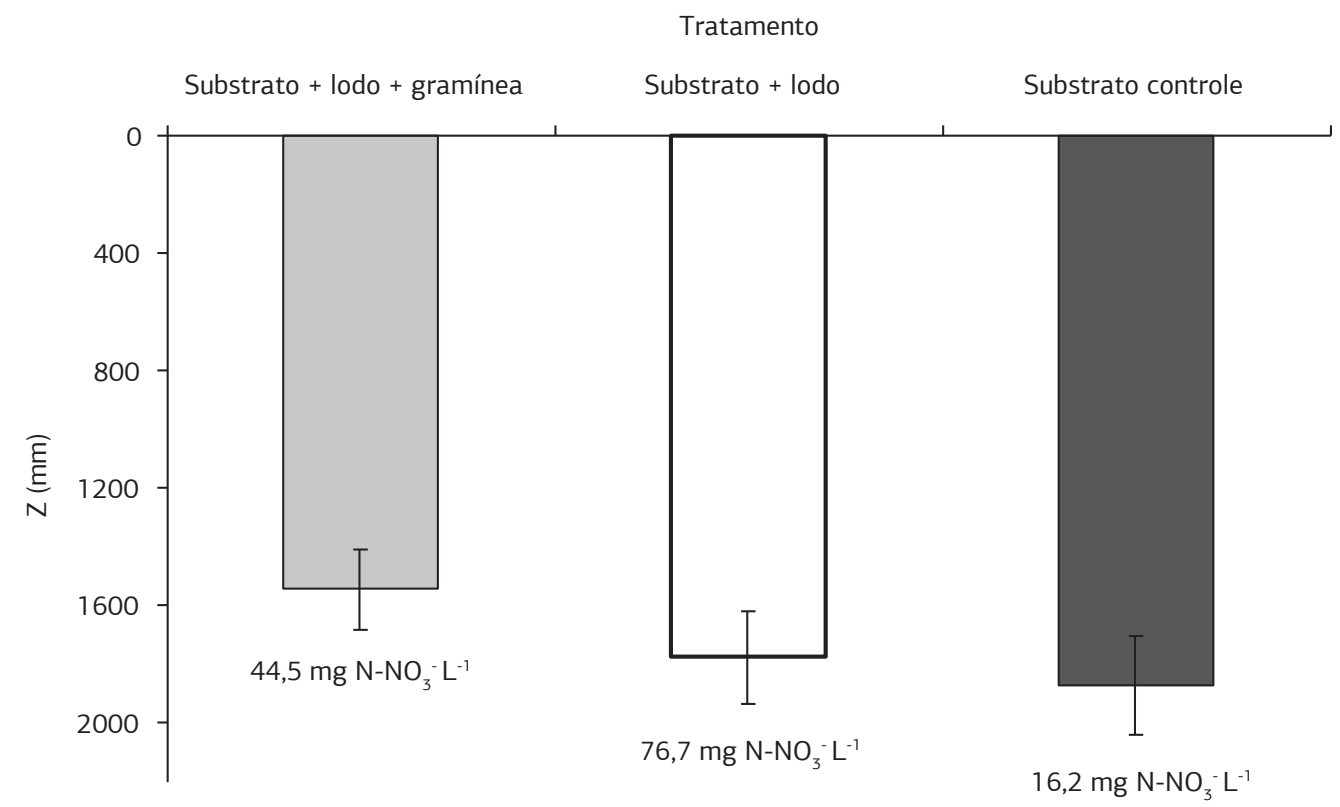

Figura 4. Profundidade anual de infiltração $(Z)$ e concentração de $\mathrm{NO}_{3}^{-}$nos lixiviados dos substratos tratados e do controle (média de dez repetiçóes \pm desvio-padrão). 
demanda que o aquífero subterrâneo esteja a pelo menos 4,5 m de profundidade, caso a camada superficial náo seja coberta por um estrato herbáceo. O estabelecimento de gramíneas no local permitiria que o aquífero estivesse a 2,7 $\mathrm{m}$ de profundidade.

\section{AGRADECIMENTOS}

Os autores agradecem o apoio prestado pelo Laboratório de Termobiologia da Universidade de Brasília, Laboratório Geoquímica da Universidade de Brasília e por seus docentes e técnicos, sem o qual não seria possível realizar este trabalho.

\section{REFERÊNCIAS}

ANDRADE, C.A; DE OLIVEIRA, C.; CERRI, C.C. Cinética de degradação da matéria orgânica de biossólidos após aplicação no solo e relação com a composição química inicial. Bragantia, v.65, p.659-668, 2006.

ANJOS, A.R.M.; MATTIAZZO, M.E.; Lixiviaçấo de íons inorgânicos em solos repetidamente tratados com biossólido. Revista Brasileira de Ciências do Solo, v.24, p.927-938, 2000.

BENTO, M.A.B. Avaliação da qualidade dos substratos minerados em cinco cascalheiras revegetadas no Distrito Federal. 2009. 116f. Dissertação (Mestrado em Ciências Florestais) - Departamento de Engenharia Florestal, Universidade de Brasília, Brasília.

BOEIRA, R.C.; MAXIMILIANO, V.C.B. Mineralização de compostos nitrogenados de lodos de esgoto na quinta aplicaçấo em Latossolo. Revista Brasileira de Ciência do Solo, v.33, p.711-722, 2009.

CAESB. Plano de aplicação do lodo de esgoto para recuperação de áreas degradadas - Jazida de cascalho laterítico Corujas. Processo $n^{\circ}$ IBAMA 02008.001445/02-61. 2005, 20p. (Ilustrado, Mimeografado)

CASSEL, D.K.; NIELSEN, D.R. Field capacity and available water capacity. In: KLUTE A (Ed.). Methods of soil analysis Part 1: Physical Methods. Madison: American Society of Agronomy; Soil Science Society of America, 1986. p.901-926.

CONAM/DF - Conselho de Meio Ambiente do Distrito Federal. Resoluçáo n.003/2006, de 18/7/2006; Diário Oficial do Distrito Federal, n.138, 20/7/2006, p.10.

CONAMA - Conselho Nacional do Meio Ambiente. Resolução n: 375/2006, de 29/8/2006. Disponível em: http://www.mma.gov.br/ port/conama/legiano/. Acesso em 29 de setembro de 2006.

CORRÊA, R.S.; BAPTISTA, G.M.M.; BALDUÍNO, A.P.C.; SILVA, L.C.R. Eficiência agronômica de dois resíduos orgânicos na revegetaçáo do horizonte $\mathrm{C}$ de um Latossolo Vermelho. Revista Ciência Agronômica, v.39, p.503-510, 2008.

CORREAA, R.S.; WHITE, R.E.; WEATHERLEY, A.J. Modelling the risk of nitrate leaching from two soils amended with five different biosolids. Revista Brasileira de Ciência do Solo, v.29, p.619-626, 2005.

DE MARIA, I.C.; KOCSSI, M.A.; DECHEN, S.C.F. Agregação do solo em área que recebeu lodo de esgoto. Bragantia, v.66, p.291298, 2007.

DYNIA, J. F.; Nitrate retention and leaching in variable charge soils of a watershed in São Paulo State, Brazil. Communications in Soil Science and Plant Analysis, v.31, p.777-791, 2000.

EDIS, R. Transfer function modelling of bromite and nitrate leaching through soil with and without plants. 1998. 277f. Thesis (Ph.D. in Soil Science) - Institute of Land and Food Resources, University of Melbourne, Australia.

EMPRESA BRASILEIRA DE PESQUISA AGROPECUÁRIA EMBRAPA. Sistema brasileiro de classificação de solos. Brasília: Serviço de Produção de Informação, 1999. 412p.

HAERING, K.C.; DANIELS, W.L.; FEAGLEY, S.E. Reclaiming mined lands with biosolids, manures, and papermill sludges. In: BARTELS, J. (Ed.). Reclamation of drastically disturbed lands. Madison: American Society of Agronomy; Crop Service Society of America; Soil Science Society of America, 2000. p.615-644.

HAYNES, R.J.; MURTAZA, G., NAIDU, R. Inorganic and organic constituents and contaminants of biosolids: implications for land application. Advances in Agronomy, v.104, p.165-267, 2009.

INMET. Instituto Nacional de Meteorologia. Disponível em: < http://www.inmet.gov.br/> Acesso em 7 de janeiro de 2007.

LAVERMAN, A.M.; ZOOMER, H.R.; VAN VERSEVELD, H.A.; VERHOEF, H.A. Temporal and spatial variation of nitrogen transformations in a coniferous forest soil. Soil Biology \& Biochemistry, v.32, p.1661-1670, 2000.

NÓVOA-MUÑOZ, J.C.; SIMAL-GÁNDARA, J; FERNÁNDEZCALVIÑO, D; LÓPEZ-PERIAGO, E.; ARIAS-ESTÉVEZ, M. Changes in soil properties and in the growth of Lolium multiflorum in an acid soil amended with a solid waste from wineries. Bioresource Technology, v.99, p.6771- 6779, 2008.

O'DOWD, R.W.; BARRACLOUGH, D.; HOPKINS, D.W. Nitrogen and carbon mineralisation in soil amended with D and L-leucine. Soil Biology \& Biochemistry, v.31, p.1573-1578, 1999.

O'KELLY, B. Effect of biodegradation on the consolidation properties of a dewatered municipal sewage sludge. Waste Management, v.28, p.1395-1405, 2008.

OLIVEIRA, F.C.; MATTIAZZO, M.E.; MARCIANO. C.R. MORAES, S.O. Lixiviaçấo de nitrato em um Latossolo Amarelo distrófico tratado com lodo de esgoto e cultivado com cana-deaçúcar. Scientia Agricola, v.58, p.171-180, 2001.

PENGCHENG, G.; XINBAO, T.; YANAN, T.; YINGXU, C. Application of sewage sludge compost on highway embankments. Waste Management, v.28, p.1630-1636, 2008.

PIOVESAN, R.P.; FAVARETTO, N.; PAULETTI, V.; MOTTA, A.C.V.; REISSMANN, C.B. Perdas de nutrientes via subsuperfície 
em colunas de solo sob fertilização mineral e orgânica. Revista Brasileira de Ciência do Solo, v.33, p.757-766, 2009.

PLACHÁ, I.; VENGLOVSKÝ, J.; MAKOVA, Z.; MARTINÉZ, J. The elimination of Salmonella typhimurium in sewage sludge by aerobic mesophilic stabilization and lime hydrated stabilization. Bioresource Technology, v.99, p.4269-4274, 2008.

POLGASE, P.J.; ROBINSON, M.B. Sustainable use of biosolids in plantation forests. In: INTERNATIONAL CONFERENCE - CONTAMINANTS AND THE SOIL ENVIRONMENT, 1., Adelaide, 1996. Annals... Adelaide: Australian Soil Science Society, 1996. p.121-122.

RATHOD, P.H.; PATEL, J.C.; SHAH, M.R.; JHALA, A.J. Recycling gamma-irradiated sewage sludge as fertilizer: a case study using onion (Alium cepa). Applied Soil Ecology, v.41, p.223- 233, 2009.

SHAFFER, M.J; HALVORSON, A.D.; PIERCE, F.J. Nitrate leaching and economic analysis package (NLEAP): model description and application. In: FOLLETT, R.F.; KEENEY, D.R.; CRUSE, R.M. (Eds.). Managing nitrogen for groundwater quality and farm profitability. Madison: Soil Science Society of America, 1991. p.285-332.

SKOOG, D.A.; HOLLER, F. J.; NIEMAN, T.A. Princípios de Análise Instrumental. 5.ed. Porto Alegre: Bookman, 2002. 836p.

VAN KESSEL, J.S., REEVES, III J.B., MEISINGER, J.J. Nitrogen and carbon mineralisation of potential manure components. Journal of Environmental Quality, v.29, p.1669-1677, 2000.

VIEIRA, R.F; CARDOSO, A.M. Variações nos teores de nitrogênio mineral em solo suplementado com lodo de esgoto. Pesquisa Agropecuária Brasileira, v.38, p.867-874, 2003.

WHITE, R.E. Principles and practices of soil science: the soil as a natural resource. 3.ed. Melbourne: Blackwell Science, 1997. $348 \mathrm{p}$.

WHITE, R.E.; HENG, L.K.; EDIS, R.B. Transfer function approaches to modeling solute transport in soils. In: MA, H.M.S.L. (Ed.). Physical Nonequilibrium in soils: modeling and application. Michigan: Ann Arbor Press, 1998. p.311-347. 